\title{
The analysis of thermal state of catalytic converter depending on fuel supply and engine load using thermo-vision
}

The paper discusses the problem of thermal state of three-way catalytic converter depending on engine load with spark ignition fueled with gasoline and natural gas. The measurements on the test bench were performed, during which the temperature of the exhaust gases in the exhaust system was measured with the help of thermocouples, and at the same time, the track of the thermal state of the catalytic converter was monitored using thermo-vision camera. The stable work of engine with different rotation speed and values of load was considered together with transient states. The results of the measurements were presented in forms of charts and selected thermo-grams, qualitatively presenting the issue of thermal state of the catalytic converter.

Key words: catalytic converter, thermo-vision, thermal state, emissivity

\section{Introduction}

The degree of conversion of the toxic exhaust gas components by the catalytic converter depends primarily on the composition of the fuel-air mixture and catalytic converter temperature. For proper operation of the catalytic converter it is required to heat it up to $300^{\circ} \mathrm{C}[1,7,8]$. The operating time is also important, because chemically aggressive fumes and variable temperature values cause aging of the converter which results in a decrease in conversion rate and increase of light-off temperature [7, 8].

The thermal state of the catalytic converter results from the engine's operating parameters, such as the load and the rotational speed. In the first phase, after the engine's cold start, there occurs high heat loss in the exhaust fumes resulting from increased heat exchange between the cold engine elements located in the exhaust gas flow path and exhaust gases. Because of its high heat capacity, the catalytic converter causes a significantly greater temperature reduction of fumes than the conduit between the outlet manifold and the catalytic converter [12, 14]. Measurements made during engine warm-up, both idle and under load, showed a constant fumes temperature of $50^{\circ} \mathrm{C}$ behind the catalytic converter for about 50-60 seconds after starting the engine, despite a very rapid rise in exhaust fumes temperature before the catalytic converter. This relationship indicates the intense heat transfer of the fumes into the converter cores. At this time there are no exothermal reactions of oxidation of $\mathrm{CO}$ and $\mathrm{HC}$ [14]. The catalytic converter warm- up period to operating temperature is dependent on the operating conditions of the engine and may last up to several minutes [14]. However, even after the engine has been warmed up, the operating conditions of the converter are not stable. This is directly due to the characteristics of the engine's performance in the vehicle, which is characterized by frequent changes in rotational speed and load, which directly affects the exhaust gas temperature.

Therefore, continuing previous work, the catalytic converter's thermal state was measured using a thermo-vision camera, taking into account the different load conditions of the engine, as well as the fuel supply with petrol and natural gas. During the experiment, the acoustic data was collected and will be analyzed in a separate article.

\section{Measurement stand}

The measurements were performed on an engine dynamometer fitted with a straight four-cylinder spark ignition engine (Fiat 170A1.00) of the displacement of $900 \mathrm{~cm}^{3}$. The engine has a maximum power of $30 \mathrm{~kW}$ (at rotation speed $5500 \mathrm{rpm}$ ) and a maximum torque of $65 \mathrm{Nm}$ (at rotation speed $3000 \mathrm{rpm}$ ). The engine exhaust system was fitted with a serially manufactured three-way catalytic converter. In an insulated catalytic converter casing, two ceramic support monoliths were fitted of a circular cross-section (diameter of approx. $90 \mathrm{~mm}$ ) and the length of approx. 75 $\mathrm{mm}$ each, divided by a gap of approx. $8 \mathrm{~mm}$. The distance between the exhaust manifold and the catalytic converter was $250 \mathrm{~mm}$. During the measurements, the engine was fueled with unleaded fuel (LO 95) and natural gas.

Due to the specific purpose of the investigations the temperature was measured at exhaust manifold and behind the catalytic converter. The coolant temperature in the cylinder head was also measured serving the purpose of validation of the engine temperature and intake air temperature monitoring the ambient conditions (engine operating conditions). The temperature measurements were performed with $\mathrm{K}$ thermocouples and the results were continuously recorded by NI card with the measurement resolution of $2 \mathrm{~s}$.

At the same time the recording of the thermal state of the catalytic converter was realized with a thermo-graphic camera (Flir T335). Prior to the measurement, the following parameters were set in the camera: emissivity of the object under investigation, ambient temperature (reflected apparent temperature), atmospheric temperature, air humidity and distance from the object tested [6]. That is why the main measurements were preceded by preliminary measurements consisting of the determination of the thermal emission rate on the surface of the elements on which the thermal state was recorded (the determined emission coefficient on the surface of the catalytic converter was $\varepsilon=0.75$ ) and determining appropriate temperature ranges and operating parameters of the thermo-graphic camera. 
Additionally, the excess air coefficient $\lambda$ was measured and recorded along with the exhaust gas composition downstream of the catalytic converter with a 5 - gas analyzer Capelec CAP 3201.

Besides that, acoustic data was collected using the SVAN 948 sound level meter and the Zoom H4n recorder. Equivalent sound pressure level in $1 / 3$ octave bands and audio signal was recorded. The time interval using a sound level meter was set at $30 \mathrm{~s}$, thus obtaining 6 samples from each engine cycle.

\section{Thermo-graphic measurements}

Thermo-vision (thermo-graphy, thermal imaging) deals with the detection, registration, processing and visualization of infrared radiation [11]. It is currently considered one of the most interesting diagnostic and observation methods. It is used in the power industry, construction, metallurgy, environmental research, medicine, scientific research and many other fields $[2,3,4,9,10]$. The wide use of thermovision is due to a number of advantages of measuring systems based on thermal analysis of the tested objects. One of such important advantages is the non-contact and noninvasive measurement of the examined objects, which in most applications, is a fundamental criterion for the use of thermal imaging.

Devices for measuring the energy of the examined object are thermo-vision cameras, consisting of an optical system, an infrared radiation detector, an electronic amplification path, a processing and a visualization. Flir T335 thermo-vision cameras are used for measurements that are included in the work. The camera's operating temperature range is -20 to $+650^{\circ} \mathrm{C}$ and the temperature measurement error is $\pm 2^{\circ} \mathrm{C}$ or $\pm 2 \%$ of the measured value. The camera used is equipped with a microbolometric matrix with a resolution of $320 \times 240$ pixels, a $25 \times 18.75^{\circ}$ lens and is characterized by a sensitivity of N.E.T.D. $0.05^{\circ} \mathrm{C}$.

In thermo-vision measurements we use the emission of electromagnetic radiation by every object whose temperature is greater than absolute zero. The electromagnetic spectrum is divided into a number of wavelength areas that are distinguished by the methods used for radiation detection. There is no fundamental difference between radiation in different bands of electromagnetic spectrum. All of them are subject to the same laws and differ only in wavelength. In thermo-graphic studies, part of the electromagnetic spectrum is used in the infrared range. The value of the emitted energy increases with the increase in the object temperature, which allows it to measure its temperature by measuring the emitted energy value, especially in the infrared radiation band. The intensity of electromagnetic radiation depends on the temperature and features of the surface of the object [13]. The resulting thermo-gram is a representation of the temperature distribution on the surface of the observed object.

Unfortunately, this method is endangered by a very wide range of errors, which are due both to human factors, measurement conditions, and the nature of measurement as well as to the technology used. Despite such great possibilities of thermo-vision, it is extremely easy to make wrong measurements or misinterpret the received thermo-grams. That is why it is crucial to optimize the selection of parame- ters to eliminate measurement errors. The energy received by the thermo-vision device does not only depend on the object's temperature but also on the emissivity of the surface. Radiation comes also from the environment and is reflected by the object tested. To measure the temperature accurately using a thermo-vision camera one should make up different sources of radiation by entering specific parameters such as (Fig. 1):

- emissivity of the object,

- ambient temperature (reflected apparent temperature),

- atmospheric temperature,

- relative humidity,

- distance of the object tested from the camera.

Emissivity is the most important, from a practical point of view, parameter of the object necessary to carry out proper measurement of the thermo-vision device. This is a measure of the intensity of the radiation (surface area) emitted by the object to the radiant intensity of the black body surface at the same temperature $[5,11]$. Although emissivity depends on many factors, there are tables of values for this parameter in the literature for different materials. In this case it should be noted that the values given in the tables are only guidelines and may differ from the object being measured. In order to obtain the exact emissivity value for a specific study it becomes necessary to determine it oneself.

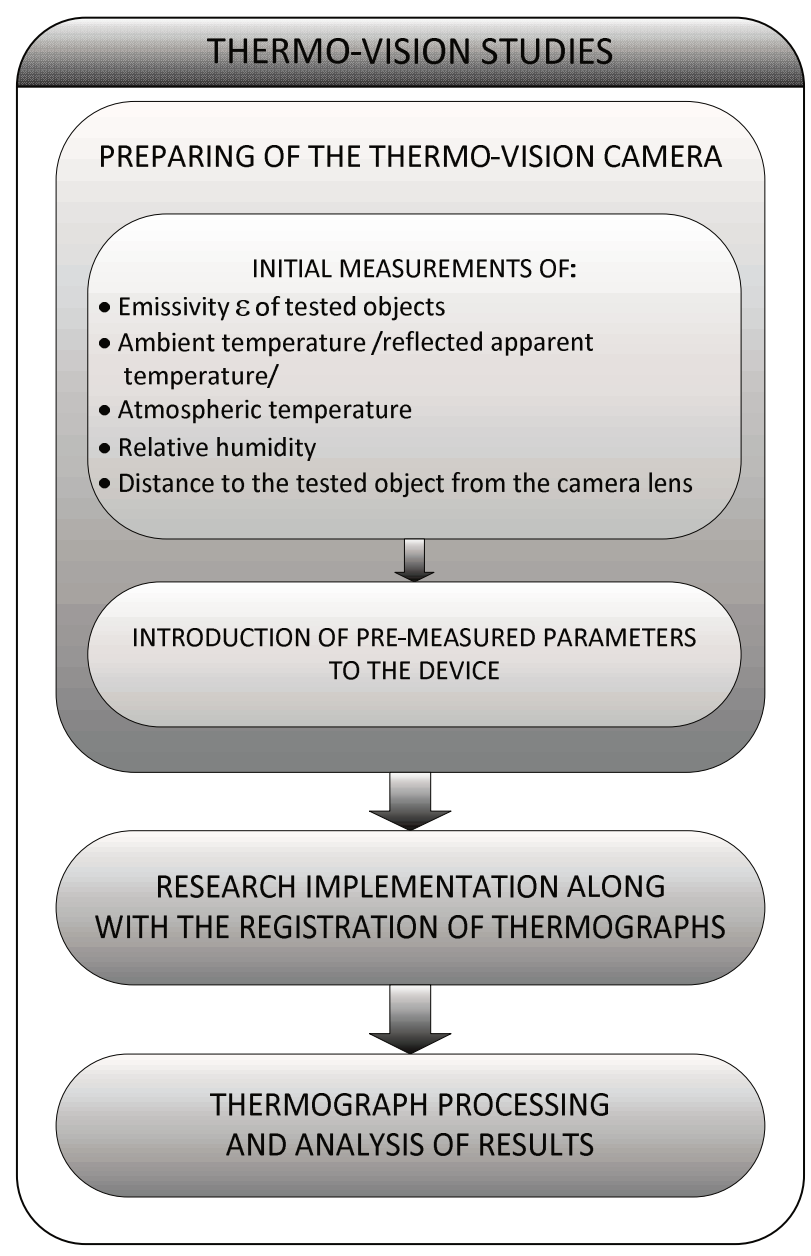

Fig. 1. Thermo-graphic measurement algorithm 
During the measurements the emissivity of the test surfaces was determined using a thermo-vision device. In order to determine the emissivity of a given surface, a tape of known emissivity $(\varepsilon=0.95)$ should be placed on its fragment, which will constitute the measurement base. At the same time, the tape's emissivity is entered into the camera's settings. After waiting for some time to warm up a given surface (the material emissivity is measured at a temperature higher than the ambient temperature), the temperature on the tape surface is measured by the thermo-vision camera. This value will be the actual temperature. In the next step, the emissivity is being changes until the values measured on the tape and the test surface are the same. The emissivity set in this way corresponds with the emissivity of the surface of the object being measured

The ambient temperature (reflected apparent temperature) is the reflected radiation from the test object or objects in its environment. Proper compensation of reflected radiation is particularly important for objects of low emissivity and when there is a strong heat source near the object $[5$, 11].

Distance is the distance separating the object from the camera. It serves to compensate both the influence of the radiation of the atmosphere itself, but also for absorption and diffusion of radiation through the atmosphere between the camera and the object tested [5, 11].

\section{Results and analysis}

For each kind of fuel the measurements started in the same ambient conditions, while the thermal state of the catalytic converter was recorded after the engine was warmed up. On the basis of preliminary measurements, for the main measurements, the engine working with a constant speed of $3000 \mathrm{rpm}$ was selected. The load was changed from $40 \mathrm{Nm}$ to $10 \mathrm{Nm}$ and then from $10 \mathrm{Nm}$ to $40 \mathrm{Nm}$, with a $10 \mathrm{Nm}$ measurement step. For each engine load, the measurement duration was approximately 5 minutes. Registration of results was conducted continuously. All of the graphs presented in the work include the measurement results as a function of time.

The coolant temperature values in the cylinder head and the intake air of the engine for the two series are shown in Fig. 2. These measurements were used to verify the repetition of the engine conditions on the stand and the engine's thermal state.

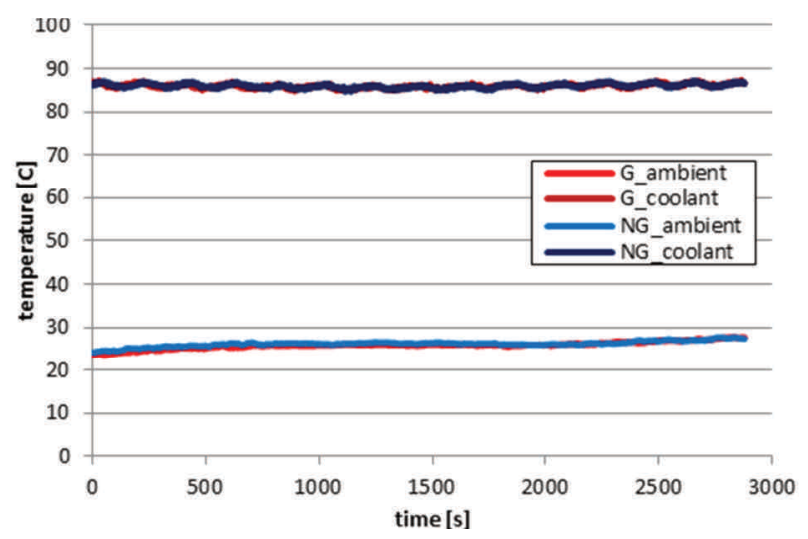

Fig. 2. Air temperature in intake manifold and coolant temperature in the cylinder head
During the supply of the engine with petrol, the exhaust gas temperature in the exhaust manifold varied between $730^{\circ} \mathrm{C}$ and $660^{\circ} \mathrm{C}$, while in the pipe behind the catalytic converter from $660^{\circ} \mathrm{C}$ to $550^{\circ} \mathrm{C}$. During the supply of the engine with natural gas, adequate temperature ranges were $710^{\circ} \mathrm{C}$ to $630^{\circ} \mathrm{C}$ for the exhaust manifold and $630^{\circ} \mathrm{C}$ to $520^{\circ} \mathrm{C}$ for the exhaust pipe. Changing the load, both for smaller and larger ones, resulted in a $20 \mathrm{~K}$ change in exhaust manifold temperature for a petrol powered engine and about $30 \mathrm{~K}$ for a gas powered engine for about $10-14 \mathrm{sec}-$ onds. During the next few minutes of engine working with constant load a further slow change in temperature followed of about $10 \mathrm{~K}$. Changes in the exhaust gas temperature behind the catalytic converter are considerably higher than in the exhaust manifold and are much slower, as illustrated in Fig. 3.

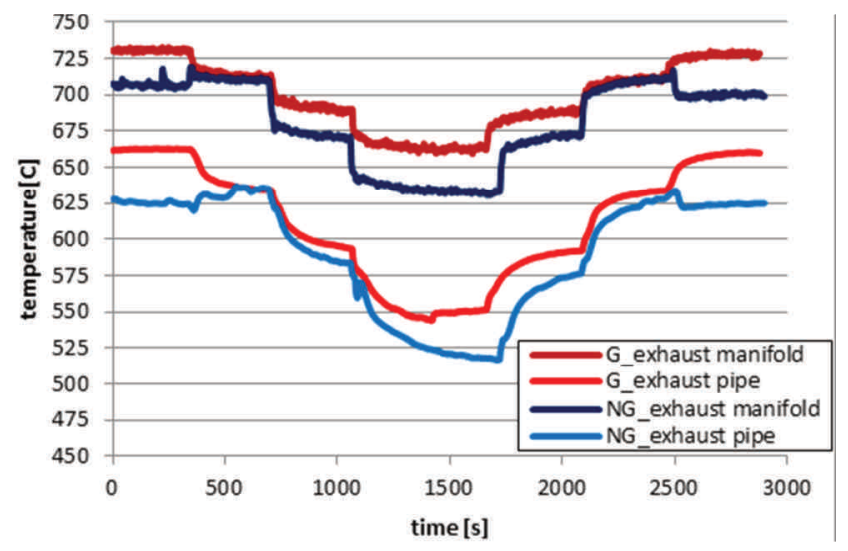

Fig. 3. Exhaust gas temperature in the exhaust manifold and in the pipe behind the catalytic converter

The smaller the engine load is, the higher the exhaust gas temperature difference is between the exhaust manifold and the pipe behind the catalytic converter. This is directly related with the mass of exhaust gases flowing through the exhaust system and therefore with their velocity which results in the time at which heat is exchanged between exhaust gases and exhaust system components.

As the load is reduced in the range of 30 to $10 \mathrm{Nm}$, the difference between the exhaust gas temperature values for the petrol and natural gas powered engine increases a can be seen both in the exhaust manifold and in the pipe behind the catalytic converter. This is due to the constant value of the air excess coefficient $(\lambda=1)$ of the air - gas mixture (Table 2) and the decreasing air excess coefficient from 1.16 to 1.08 for the petrol - air mixture (Table 1) together with decreasing load in this range. The types of fuel used are characterized by a significant difference in the stoichiometric constant (which was taken into consideration during the gas analyzer calibration for each type of fuel). If the petrol powered engine was powered with Lambda sensor feedback, the exhaust gas temperature difference for both fuels would be similar for different loads. For a $40 \mathrm{Nm}$ load, the natural gas supply system was not sufficiently efficient and the Lambda was $1.18-1.28$, which was also reflected in the exhaust gas temperature values. 
At the same time, recording of the temperature distribution across the surface of the entire catalytic converter allows you to observe the differences in the degree of heating of its components. The amount of emitted energy results, among other things, from the materials used and the number of layers. There are insulating mats on the surface of both cores which limit the amount of radiation, but the occurrence of the same layers does not affect the value of the temperature difference. Therefore, the analysis of images from the thermo-vision camera gives the possibility of conducting a comparative analysis of a qualitative nature.

Table 1. Emissions of exhaust components measured behind catalytic converter - petrol powered engine

\begin{tabular}{|l|c|c|c|c|c|c|}
\hline Load & $\begin{array}{c}\mathrm{CO} \\
{[\% \text { vol }]}\end{array}$ & $\begin{array}{c}\mathrm{CO}_{2} \\
{[\% \text { vol }]}\end{array}$ & $\begin{array}{c}\mathrm{HC} \\
{[\mathrm{ppm}} \\
\text { vol }]\end{array}$ & $\begin{array}{c}\mathrm{O}_{2} \\
{[\% \text { vol }]}\end{array}$ & $\begin{array}{c}\mathrm{NO}_{\mathrm{x}} \\
{[\mathrm{ppm}} \\
\text { vol] }\end{array}$ & Lambda \\
\hline $40 \mathrm{Nm}$ & 0 & 13.3 & 3 & 2.30 & 1893 & 1.121 \\
\hline $30 \mathrm{Nm} *$ & 0 & 13 & 0 & 2.77 & 1061 & 1.149 \\
\hline $30 \mathrm{Nm}$ & 0 & 13 & 1 & 2.77 & 913 & 1.150 \\
\hline $20 \mathrm{Nm} *$ & 0 & 13.3 & 1 & 2.25 & 684 & 1.119 \\
\hline $20 \mathrm{Nm}$ & 0 & 13.3 & 1 & 2.24 & 603 & 1.118 \\
\hline $10 \mathrm{Nm} *$ & 0 & 13.7 & 0 & 1.58 & 395 & 1.081 \\
\hline $10 \mathrm{Nm}$ & 0 & 13.7 & 1 & 1.57 & 328 & 1.080 \\
\hline $20 \mathrm{Nm} *$ & 0 & 13.3 & 6 & 2.29 & 542 & 1.121 \\
\hline $20 \mathrm{Nm}$ & 0 & 13.3 & 2 & 2.32 & 556 & 1.122 \\
\hline $30 \mathrm{Nm} *$ & 0 & 12.9 & 4 & 2.96 & 673 & 1.161 \\
\hline $30 \mathrm{Nm}$ & 0 & 12.9 & 0 & 2.95 & 714 & 1.160 \\
\hline $40 \mathrm{Nm} *$ & 0 & 13.2 & 7 & 2.41 & 1318 & 1.128 \\
\hline $40 \mathrm{Nm}$ & 0 & 13.3 & 4 & 2.36 & 1440 & 1.125 \\
\hline
\end{tabular}

*right after load change

Table 2. Emission of exhaust components measured behind catalytic converter - natural gas powered engine

\begin{tabular}{|l|c|c|c|c|c|c|}
\hline \multicolumn{1}{|c|}{ Load } & $\begin{array}{c}\mathrm{CO} \\
{[\% \text { vol }]}\end{array}$ & $\begin{array}{c}\mathrm{CO}_{2} \\
{[\% \text { vol }]}\end{array}$ & $\begin{array}{c}\mathrm{HC} \\
{[\mathrm{ppm}} \\
\text { vol }]\end{array}$ & $\begin{array}{c}\mathrm{O}_{2} \\
{[\% \text { vol }]}\end{array}$ & $\begin{array}{c}\mathrm{NO}_{\mathrm{x}} \\
{[\mathrm{ppm}} \\
\text { vol }]\end{array}$ & Lambda \\
\hline $40 \mathrm{Nm}$ & 0 & 10.2 & 10 & 2.61 & 1062 & 1.179 \\
\hline $30 \mathrm{Nm} *$ & 0 & 11.5 & 13 & 0.10 & 923 & 1.005 \\
\hline $30 \mathrm{Nm}$ & 0 & 11.6 & 12 & 0.04 & 482 & 1.001 \\
\hline $20 \mathrm{Nm} *$ & 0 & 11.6 & 14 & 0 & 44 & 0.999 \\
\hline $20 \mathrm{Nm}$ & 0 & 11.6 & 12 & 0 & 41 & 0.999 \\
\hline $10 \mathrm{Nm} *$ & 0 & 11.6 & 12 & 0.03 & 187 & 1.001 \\
\hline $10 \mathrm{Nm}$ & 0 & 11.6 & 11 & 0.08 & 212 & 1.004 \\
\hline $20 \mathrm{Nm} *$ & 0 & 11.6 & 12 & 0.06 & 497 & 1.003 \\
\hline $20 \mathrm{Nm}$ & 0 & 11.6 & 13 & 0.05 & 511 & 1.002 \\
\hline $30 \mathrm{Nm} *$ & 0 & 11.6 & 13 & 0.07 & 795 & 1.004 \\
\hline $30 \mathrm{Nm}$ & 0 & 11.6 & 12 & 0.03 & 689 & 1.001 \\
\hline $40 \mathrm{Nm} *$ & 0 & 9.6 & 9 & 3.68 & 615 & 1.269 \\
\hline $40 \mathrm{Nm}$ & 0 & 9.5 & 10 & 3.82 & 560 & 1.282 \\
\hline
\end{tabular}

*right after load change

The curves in Figures 4 and 5 show the minimum, maximum and average temperatures read from the thermograms according to the procedure described in [14] for the first and second catalytic converter cores for both fuels respectively. The temperature values on the surface of the first core are higher, and so the minimum is about $15-30 \mathrm{~K}$, the maximum is about $40-55 \mathrm{~K}$, and the average is $25-30$ $\mathrm{K}$, regardless of the fuel used. Similarly, for both fuels and on both cores, the mean difference between the minimum and average values is $50-60 \mathrm{~K}$. On the other hand, the delta for the average and maximum values for the first core is between $90-110 \mathrm{~K}$ and the second is about 70-90 K. The thermograms show the causes of numerical differences (Fig. 6). The temperature distribution on the surface of the first core is very different, while for the second it is evenly distributed, with much lower temperature gradients. The maximum intensity of the maximum values, resulting in large differences between cores, occurs in the initial part of the first core, where, despite the sealing mat, there is a direct contact between the incoming exhaust gas and the core housing and its heating.

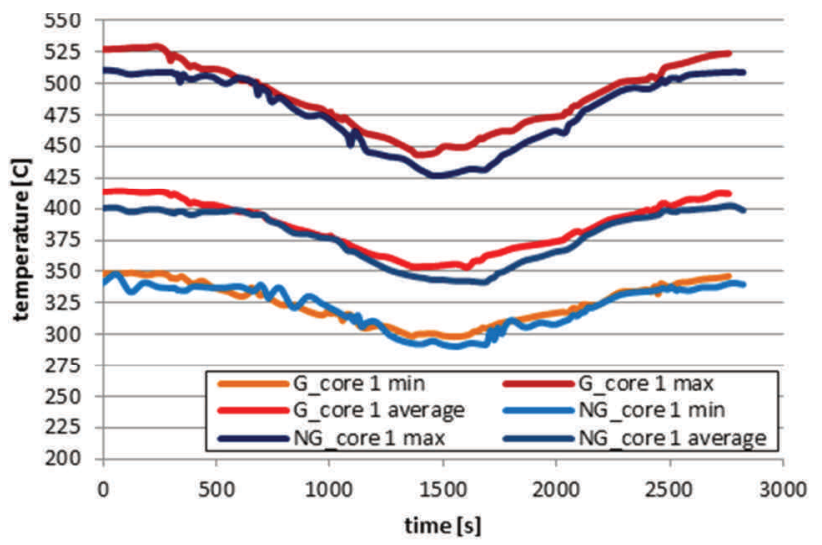

Fig. 4. Temperature values on the surface of the first core derived from thermo-grams

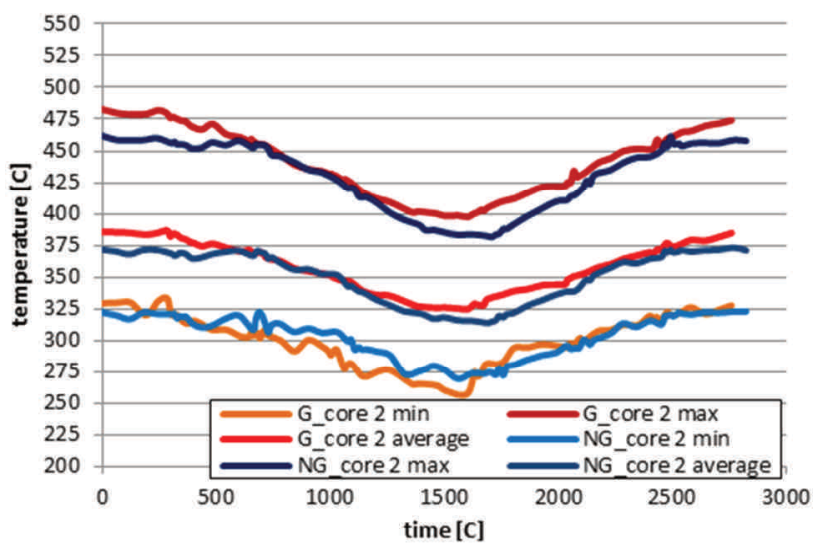

Fig. 5. Temperature values on the surface of the second core derived from thermo-grams

Considering the influence of the fuel used in the engine and the composition of the fuel - air mixture on the exhaust gas temperature, the thermo-grams of the exterior surfaces of the catalytic converter show much less difference in temperature than the thermocouples measured in the interior of the exhaust system. In addition, the curves of minimum values are characterized with high fluctuations that makes it impossible to determine the difference clearly. On the other hand, for the other curves, the tendency associated with the load and composition of the fuel - air mixture described for the thermocouple value occurs, though without clear demarcation.

The exhaust gas behind the catalytic converter (Fig. 3) and the surface of the catalytic converter (Fig. 4, Fig. 5) during the whole measurement obtained values that clearly indicate that the catalytic converter reached the correct temperature for proper operation. The carbon dioxide content of the exhaust gas reflects the chemical composition of the fuels (Table 1 and Table 2). Due to the different composition of the mixture, it is not possible to compare directly the emissions of toxic components of the exhaust gases with the environment depending on the fuel that the engine 
was powered with. In both cases of measurement, there was no carbon monoxide emission behind catalytic convertor to the atmosphere, while emission of hydrocarbons was very low, however, higher values were obtained when the engine was supplied with natural gas. This can result from the composition of the mixture and the main constituent of natural gas, i.e. methane, whose conversion rate in the catalytic converter is considerably lower than that of the higher hydrocarbons [15]. Emission of nitric oxides correlates with engine load and mixture composition.
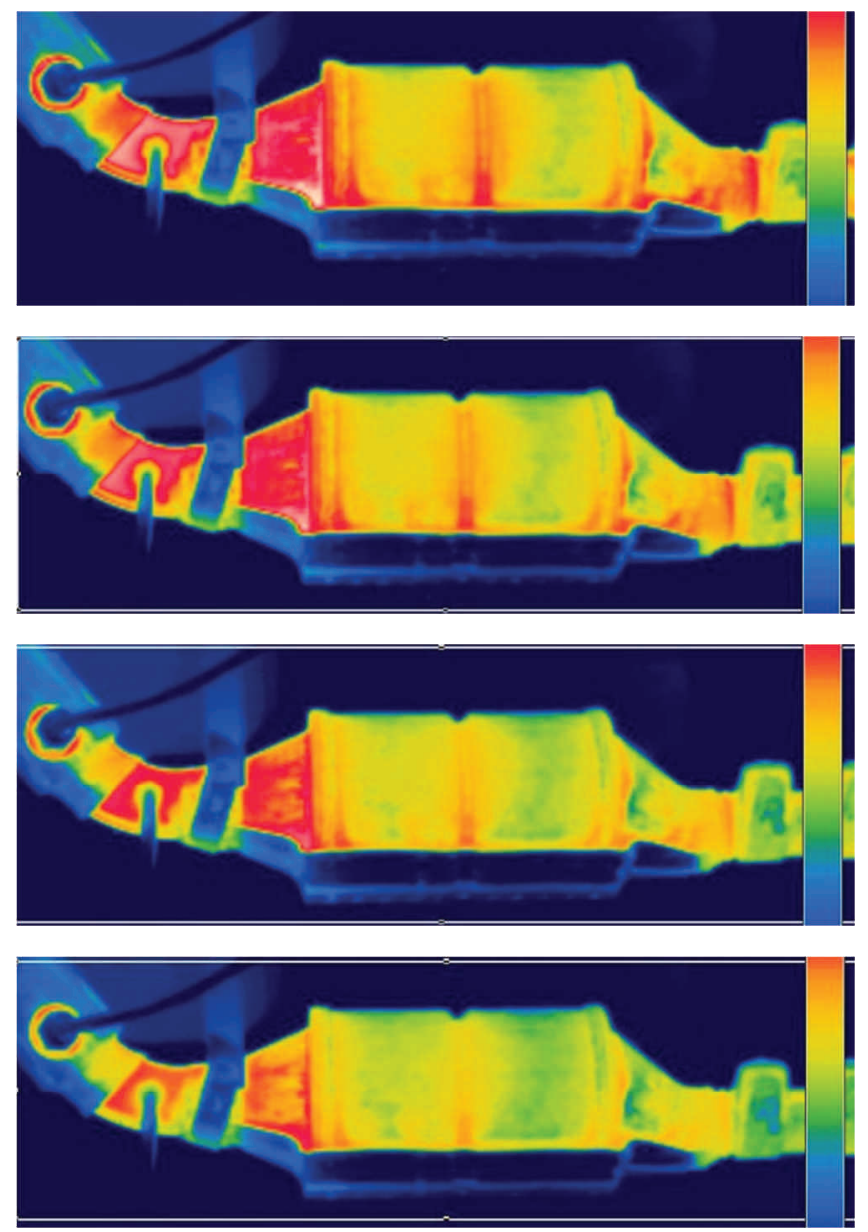

Fig. 6. Thermo-graphic images selected from the measurements - petrol supply, load: $40 \mathrm{Nm}, 30 \mathrm{Nm}, 20 \mathrm{Nm}, 10 \mathrm{Nm}$

During the analysis of the thermo-grams, besides the temperature values for the individual converter cores, the maximum temperature for the entire catalytic converter was also read. This value was present on the diffuser, which is the first element on the flow path of the exhaust gas through the catalytic converter, and in addition, the exhaust gas has direct contact with the walls. In addition, there is a change of shape, and in the immediate vicinity of the area with the highest temperature there is the cover, also occurs a sheltered section (a kind of recess), where radiation is reflected between the adjacent surfaces. Due to the shield also the impact of ambient conditions is limited. As a result, the maximum temperature is significantly higher than the temperature on the converter cores casing. That is why this temperature was compared to the temperature measured by the thermocouple behind the catalytic converter (Fig. 7 and
Fig. 8). The values obtained are less than 5 to $28 \mathrm{~K}$. Because of the lack of insulating elements, the nature of the curve is more consistent with the exhaust gas temperature than the cylindrical surface in which the cores are.

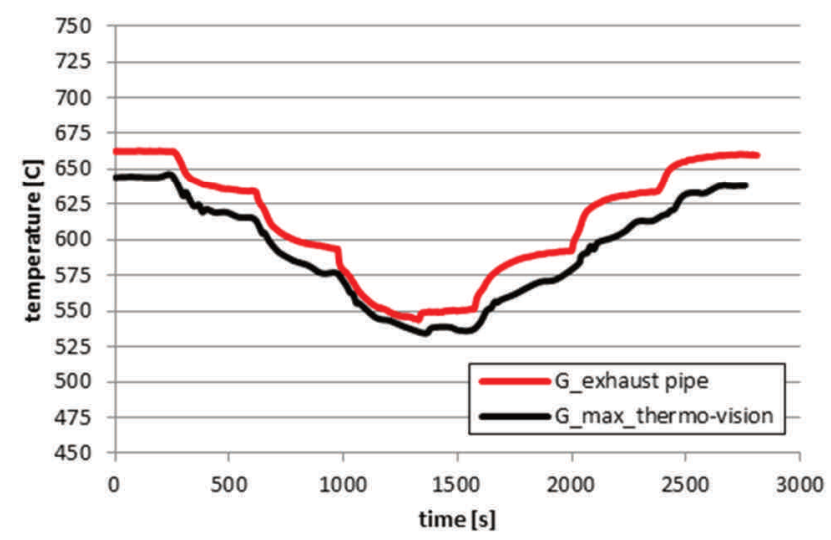

Fig. 7. Comparison of temperature values in the pipe behind the catalytic converter with the maximum from thermo-grams - for petrol

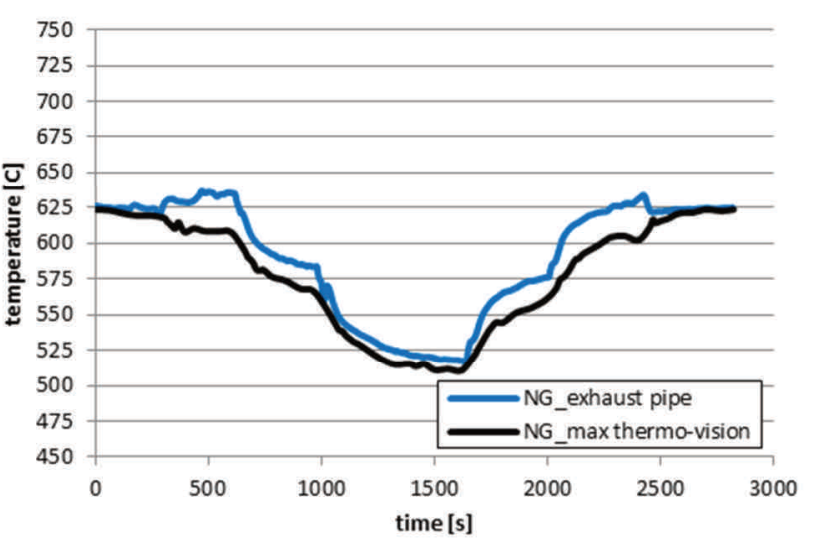

Fig. 8. Comparison of temperature values in the pipe behind the catalytic converter with the maximum of thermo-grams for natural gas

The intensity of electromagnetic radiation depends on the temperature and characteristics of the surface of the observed object. Therefore, for each object the emissivity should be individually determined. The measurements presented in this paper were focused on the heat state of the catalytic converter, so during the preliminary measurements the surface emissivity of the catalytic converter was set at $\varepsilon$ $=0.75$. As the temperature in the exhaust manifold was also measured using a thermocouple, it was reasonable to compare thermo-grams for the exhaust manifold surface as well. The use of the thermo-vision camera settings for the catalytic converter concerning other parameters (ambient temperature, atmospheric temperature, relative humidity, distance of the examined object from the camera) was appropriate because the tested objects were in the same atmospheric conditions and distance from the measuring device. Using the same emissivity, however, would result in a serious measurement error. The surface of the cast iron exhaust manifold is much more dull than the surface of the steel sheet converter housing, therefore the emissivity of the manifold is $\varepsilon=0.93$. Use of the emissivity of the converter relative to the exhaust manifold results in a difference in temperature results of about $15 \%$. Figure 9 shows the com- 
parison between the exhaust gas temperature at the exhaust manifold and the maximum temperature read from the thermo-gram (Fig. 10) with the specific emissivity for the manifold $(\varepsilon=0.93)$ and the catalytic converter $(\varepsilon=0.75)$.

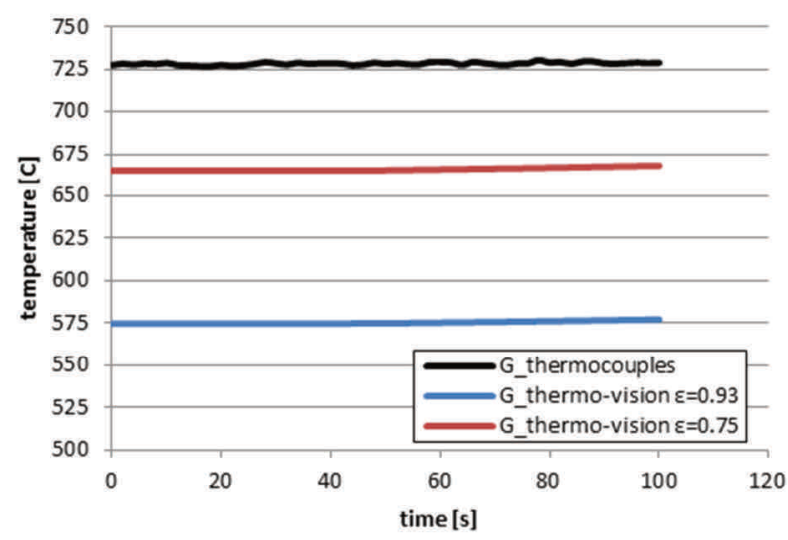

Fig. 9. Comparison of temperature values for exhaust manifold derived from thermocouple and thermo-graphic images (different emissivity)

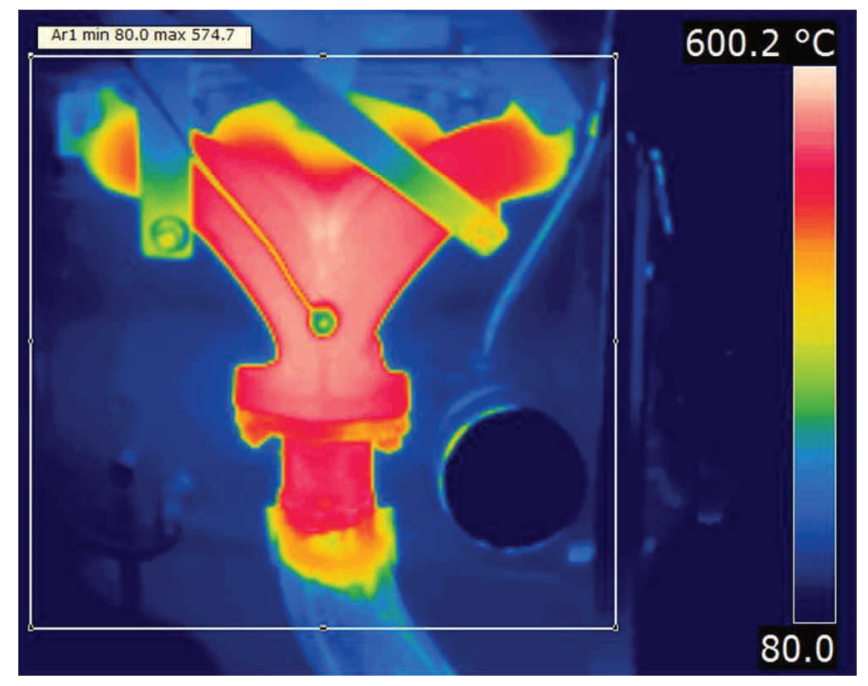

Fig. 10. Thermo-graphic image of the engine exhaust manifold (emissivity $\varepsilon=0.93)$

\section{Conclusions}

The exhaust temperature depends primarily on the load on the engine, but also on the composition of the fuel - air mixture and the type of fuel used. Measurements of the thermal state of the catalytic converter at the engine bench were made after the engine was warmed up. The exhaust gas temperature behind the catalytic converter and the catalytic converter surface indicate that during the entire measurement the converter reached the correct temperature for proper operation. However, taking into account the effect of the engine load on the difference between exhaust gas temperature between the exhaust manifold and the pipe behind the catalytic converter, the distance between the exhaust manifold and the device will be of great importance for the conversion rate achieved in the converter. Especially during the operation of the vehicle in urban conditions when most of the time the engine is running at low load or idle speed. The use of ceramic monolith is advantageous in this case because of its lower thermal conductivity and greater specific heat compared to the metal monolith.

The amount of heat radiated outside will always be smaller than the actual amount inside the device being tested, therefore, thermo-vision measurements are a qualitative and not quantitative method whose main advantage is being non-invasive. In the case of a catalytic converter, the insulating mats between the converter cores and the casing also have an effect on the temperature distribution on the surface of the converter. Nevertheless, the nature of the changes recorded by the thermocouples and the thermo-vision camera was the same; resulting from the conditions of the engine operating. The thermo-grams show differences in the degree of heating of the individual parts of the catalytic converter depending on the conditions set.

A very important aspect during thermo-vision measurements is to determine the correct operating parameters of the camera which depend on the ambient conditions and the emissivity of the tested objects. However, despite many parameters affecting the quality of thermo-vision, this technique proves useful in the thermal analysis of various objects, including engine components.

\section{Bibliography}

[1] BIELACZYC, P., MERKISZ, J., PIELECHA, J. Stan cieplny silnika spalinowego a emisja związków szkodliwych. Wydawnictwo Politechniki Poznańskiej. Poznań 2001.

[2] DAMIJAN, Z., UHRYŃSKI, A. Systemic cryotherapy influence of low temperatures on selected physiological parameters. Acta Physica Polonica A, Polska Akademia Nauk. Instytut Fizyki, Warszawa ; ISSN 0587-4246. 2012, 121(1A). Acoustic and biomedical engineering, A-38-A-41.

[3] DAMIJAN, Z., UHRYŃSKI, A. The influence of driver's working environment on thermical changes of their organism. Acta Physica Polonica A, Polska Akademia Nauk. Instytut Fizyki, Warszawa ; ISSN 0587-4246. 2010, 118(1), 35-40.

[4] DAMIJAN, Z., UHRYŃSKI, A. The effect of general low frequency vibration on energy balance of a human being. Acta Physica Polonica. A, ISSN 0587-4246. 2013, 123(6). Acoustic and biomedical engineering, 970-973.
[5] FLIR. Instrukcja obsługi. 2010.

[6] JAKUBOWSKA, T., PESZYŃSKI-DREWS, C., WIĘCEK, B. Standaryzacja w badaniach termograficznych w zastosowaniu praktycznym na przykładzie pracowni termograficznej w Centrum Diagnostyki i Terapii Laserowej Politechniki Łódzkiej. Acta Bio-Optica et Informatica Medica. 2006, 2(12), 81-84.

[7] KRUCZYŃSKI, S. Trójfunkcyjne reaktory katalityczne. Wydawnictwo ITE, Warszawa-Radom 2004.

[8] KRUCZYŃSKI, S. Eksploatacja trójfunkcyjnych reaktorów katalitycznych - dezaktywacja termiczna. Eksploatacja $i$ Niezawodność. 2012, 14(3).

[9] LEPIARCZYK, D., GAWĘDZKI, W., UHRYŃSKI, A., TARNOWSKI, J. Usage of thermo-vision in research concerning kinematic pair of friction in machines and mechanical devices. Vísnik Kï̈vs'kogo Nacional'nogo Universitetu Tehnologij ta Dizajnu. 2012, 3, 190-195. 
[10] LEPIARCZYK, D., UHRYŃSKI, A. Thermo-vision analysis of iron foundry production process concerning secondary usage of heat. Polish Journal of Environmental Studies. 2014, 23(3), 1017-1023.

[11] MADURA, H. at al. Pomiary termowizyjne w praktyce. Warszawa: Agenda Wydawnicza PAKu, 2004.

[12] RYBARZ, M., BRZEŻAŃSKI, M. Zagadnienia tworzenia się kondensatu w układzie wylotowym silnika spalinowego. Czasopismo Techniczne Mechanika. 2008, 8-M.

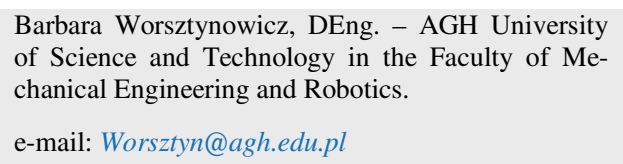

Andrzej Uhryński, DEng. - AGH University of Science and Technology in the Faculty of Mechanical Engineering and Robotics.

e-mail:uhrynski@agh.edu.pl
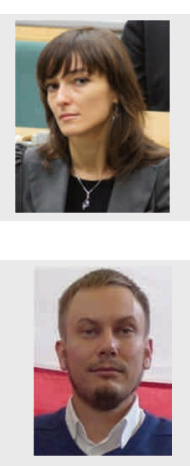

[13] WIŚNIEWSKI, S. Wymiana ciepła, WNT, Warszawa 1997.

[14] WORSZTYNOWICZ, B., UHRYNSKI, A. The analysis of heating process of catalytic converter using thermo-vision. Combustion Engines. 2015, 162(3), 41-51.

[15] WORSZTYNOWICZ, B. Influence of the mixture composition on the conversion degree of catalytic conventer during power supply of the engine with natural gas. Journal of Polish Cimac. Diagnostic, reliability and safety. 2013, 8(2).

Bartłomiej Borkowski, DEng. - AGH University of Science and Technology in the Faculty of Mechanical Engineering and Robotics.

e-mail: bborkow@agh.edu.pl

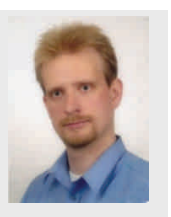

Marek Pluta, PhD - AGH University of Science and Technology in the Faculty of Mechanical Engineering and Robotics.

e-mail:Pluta@agh.edu.pl 